\title{
Estágio curricular: permanências e mudanças em um espaço tempo estruturador da formação de professores
}

\author{
José Batista Neto \\ Eliete Santiago \\ Universidade Federal de Pernambuco
}

\section{Resumo}

O estágio supervisionado na formação de professores é o objeto de estudo deste artigo, cujo objetivo é analisar as concepções de estágio, em articulação com políticas e práticas de formação de professor histórica e socialmente construídas. 0 estudo revelou as diferentes concepções assumidas por esse componente curricular das licenciaturas as quais refletem a diversidade de perspectivas de formação docente situadas em momentos históricos distintos. Estas perspectivas traduzem compreensão sobre as finalidades sociais e históricas da educação superior e da educação básica. É formulada proposição de sua organização em ciclos, bem como são discutidos desafios de sua vivência.

Palavras-chave: Estágio supervisionado. Formação de professores. Políticas de formação. 


\section{Curricular Practice Teaching: Permanence and Changes Entailed in the Space and Time of Teacher Education}

This article investigates supervised practice teaching as a part of teacher education. It aims at analyzing conceptions of practice teaching linked to socially and historically developed policies and practices of teacher education. The study revealed different conceptions taken on by this component of the undergraduate teacher education curriculum, which reflect the diversity of perspectives on teacher education, in different historical moments. These perspectives translate an understanding of the social and historical objectives of higher and basic education. An organization in cycles is proposed, and challenges experienced in the process are discussed.

Keywords: Supervised practice teachingn. Teacher education. Teacher education policies.

\section{Prácticas curriculares: permanencias y cambios en un espacio tiempo estructurador de la formación de profesores}

El objetivo de este artículo es analizar las diferentes concepciones de prácticas supervisadas articuladas con políticas histórica y socialmente construidas y cursos de formación de profesores. El estudio mostró que los distintos conceptos asumidos por ese componente curricular de las licenciaturas reflejan la diversidad de perspectivas de formación docente ubicadas en diferentes momentos históricos. Tales perspectivas expresan comprensión sobre las finalidades sociales e históricas de la educación superior y de la educación básica. Se propone su organización en ciclos y se discuten los desafíos de su vivencia.

Palabras-clave: Práctica supervisada. Formación de profesores. Políticas de formación. 


\section{Introdução}

Instituídas há mais de uma década, as Diretrizes Curriculares Nacionais para a Formação de Professores da Educação Básica (DCNFP) expressam não apenas o quadro normativo que regula a atividade formativa de docentes para esse nível de ensino, mas os debates social e acadêmico que a secundaram. Objeto de polêmicas, divergências e de incompreensões de gestores de instituições formadoras, as DCNFP dão consequência a uma determinação que reconhece uma especificidade própria desta modalidade de ensino superior e introduzem mudanças na composição e organização dos currículos dos cursos de licenciatura, graduação plena, incidência sobre carga horária e número de horas de atividade científicoacadêmica. A prática e o estágio estão entre os componentes curriculares que receberam especial atenção devido às tônicas dos debates sobre formação de professores no País.

As inquietações e questões mais recentes sobre formação docente têm sido postas em meio a uma conjuntura, de certo modo, paradoxal, uma vez que se observa, de um lado, uma expansão da demanda por profissionalização do professor e, por outro, a crise do profissionalismo e das profissões (Tardif, 2002; Mellowki; Gauthier, 2004; Veiga et al., 2005, Batista Neto, 2007). Nesse sentido, entrecruzamse movimentos com sentidos e significados distintos que se conflitam.

0 movimento em direção à profissionalização da docência avança, buscando renovar os fundamentos epistemológicos do ofício de professor. Uma epistemologia da prática profissional estaria no cerne deste primeiro movimento. Em outro sentido, o profissionalismo, que durante muito apoiou-se numa racionalidade instrumental diretamente baseada em modelos das ciências aplicadas, combinando meios e fins, se vê em uma crise que se abate sobre os conhecimentos, as estratégias e as técnicas profissionais. Tardif (2002) adverte que se vive a impressão de que a atividade profissional não disporia mais de um repertório estável de saberes, codificado e consensual, que a legitime e empodere. Essa crise introduz questionamentos sobre o modelo hegemônico de formação, baseado numa tradição universitária, dominada por uma cultura disciplinar e pelos imperativos da produção do conhecimento.

A crise do profissionalismo seria também a crise da formação profissional, suas políticas, conteúdos, relações e práticas. Ela atingiria, de cheio, o currículo, âmbito no qual se definem os conteúdos formativos, ensejando novos referenciais e diretrizes e suscitando renovação nas práticas curriculares. Questionaria a relação entre teoria e prática, conteúdo e forma, formação e exercício profissional, instituição de formação e instituição de exercício profissional, desvelando questões da intricada tessitura que constituiria a formação de professores. 
No âmbito desta pesquisa, recortamos um componente curricular dos cursos de formação inicial de professor, o estágio supervisionado. Esse componente tem inquietado pesquisadores e provocado gestores de instituições de formação e formuladores de políticas educacionais. Tomamos como questão de partida: que papel tem desempenhado o estágio curricular na formação de professores? Buscamos ainda responder: o que seria um estágio constituído como eixo estruturador da formação docente? Qual o papel da pesquisa da/na realidade escolar e educacional? Quais fundamentos informariam uma perspectiva de integração entre teoria e prática nas práticas curriculares?

0 texto está estruturado em duas partes. Discutiremos, num primeiro momento, os resultados de análise documental, com o objetivo de restituir, por meio de uma breve revisão histórica, os sentidos atribuídos por sujeitos públicos ao estágio supervisionado desde o momento em que se inseriu na formação de professores no Brasil, destacando avanços e limites de cada período histórico. Na segunda parte, a análise se debruçará sobre prática curricular implantada em uma universidade pública federal em Pernambuco: o estágio em ciclos, entendido como eixo estruturador da formação. Tecemos, por fim, considerações sobre olhares e vivências do estágio supervisionado.

\section{Estágio supervisionado na prática de formação de professores: questões iniciais}

A preocupação com o estágio, como aponta a literatura, remonta às origens dos cursos de formação de professor. Com efeito, ela informa as inquietações sobre questões que dizem respeito às relações teoria e prática, conteúdo e forma, saberes disciplinares e saberes pedagógicos, espaço de formação e espaço de exercício profissional.

Não é de surpreender, portanto, que o tema do estágio curricular em cursos de formação de professor tenha e siga se constituindo como objeto de estudos, pesquisas e ensaios analíticos (Candau; Lelis, 1983; Candau, 1986; Fávero, 1992; Zeichner, 1993; Fazenda, 1994; Piconez, 1994; Freitas 1996; Pimenta, 2001; Pimenta e Lima, 2005/2006; Batista Neto e Santiago, 2006; Rocha, 2008; Melo, 2014, entre outros), de encontros científicos (CBE, ANPEd, Anfope, Endipe) e de avaliações de órgãos gestores dos sistemas públicos de ensino (MEC e secretarias estaduais de Educação).

Estudos e pesquisas têm evidenciado os diferentes sentidos que assumem tais relações, que refletem, em definitivo, a diversidade de concepções sobre o que é formar professores, o que é ser professor, mas também o porquê, para quê e de que modo a prática, sob forma de estágio, se insere na formação. 


\section{Os diferentes sentidos do Estágio/Prática de Ensino': de como uma mera recomendação tornou-se necessidade}

A prática, como espaço tempo de formação, já ocupava, em Estados da Federação, desde a década de 1930, um lugar na legislação que regulamentava os cursos de formação do professor para o magistério no então curso primário². 0 interesse em fazer com que um estudante do curso normal realize algum tipo de prática no campo profissional, ainda no período do curso, é observado desde então. As instituições formadoras, no entanto, não responderam de forma efetiva e homogênea a essa questão. Observam-se escolas normais que, tendo reconhecido a importância do que pontuava o debate educacional, buscaram incorporar ao currículo do curso normal disciplina(s) com a finalidade de promover a iniciação profissional. No entanto, foram em maior número aquelas escolas que trataram a questão como se fosse não uma exigência, mas uma mera recomendação, eximindo-se de atendê-la. As determinações da Lei Orgânica do Ensino Normal (Brasil, 1946) para que a formação do professor primário instituísse “exercícios de observação e participação real no trabalho docente", fazendo com que se "integrem os conhecimentos teóricos e técnicos de todo o curso", bem como a criação e a manutenção de escolas primárias para demonstração e prática de ensino, não foram capazes de criar um quadro favorável. As soluções dadas a essas determinações terminaram por criar novos problemas, em virtude da concepção que as presidia. Assim, a diversidade de disciplinas incorporadas ao currículo, visando à iniciação profissional, denota a imprecisão conceitual que subsistia no tratamento do problema de como e mediante o que se poderia efetivar uma maior aproximação com o campo de exercício profissional docente. Por outro lado, a criação de escolas de aplicação reafirma, como o termo indica, o caráter aplicacionista com que são vistas as relações entre os campos da formação e do exercício profissional do professor. É demonstração do aplicacionismo o lugar, na organização curricular, que ocupam os conhecimentos da formação docente e as relações que entre eles se efetivam, na organização curricular, , segundo sua natureza: os conhecimentos teóricos, em primeiro lugar, para, em um momento final, serem eles aplicados na prática, indicando assim a iniciação profissional. Vemos instituído, a partir de então, um traço da formação docente, a dicotomia

1. Até o início dos anos 2000, a legislação federal e literatura especializada referiam-se à Prática de Ensino como estágio supervisionado na formação do professor. Para efeito desta seção, Prática de Ensino e Estágio Supervisionado serão tomados como sinônimos.

2. A referência ao contexto estadual deve-se ao fato de, só após 1930, a educação ser assumida como questão nacional, tornando-se objeto de política da União Federal e de regulamentação própria. (Saviani, 2004) 
teoria e prática, em que a primeira tem precedência e primazia sobre a segunda.

A visão de prática de iniciação profissional em curso de formação de professor desse período guarda coerência com um projeto educacional fundado na Escola Nova, em cuja base estava a defesa de uma educação escolar fundada nos princípios da laicização do ensino, da escola única e gratuita para todos, mas também enquanto projeto político em condições de reformar o indivíduo para a integração social em um contexto marcado por problemas sociais introduzidos pela industrialização e urbanização crescentes (Araújo, 2007, p. 9). A concepção de estágio que prevalece nos anos 1940, 1950 e 1960, no Brasil, expressa questões que a modernização em curso coloca para as políticas educacionais. 0 projeto educacional hegemônico forja política educacional de formação de professor, na qual ganha cada vez mais espaço uma perspectiva técnico-científica em detrimento de uma concepção humanista, o alinhamento com a educação das elites nacionais e, ainda, com os ditames da uniformidade educacional e da padronização cultural. A modernização descortina assim as possibilidades do momento histórico, mas igualmente seus limites.

Os limites da política de formação de professores podem ser vistos quando, no início dos anos 1960, Valnir Chagas, conselheiro do Conselho Federal de Educação (CFE), censura a negligência com que era tratada a dimensão prática da formação pedagógica, ainda não considerada como uma exigência na preparação desse profissional, razão pela qual reivindica o estabelecimento de novos parâmetros ${ }^{3}$. $\mathrm{Na}$ verdade, o conselheiro Chagas denuncia, por meio do Parecer CFE n. ${ }^{0}$ 292/62, os diversos problemas por que passava a formação docente no Brasil, problemas que informam o modo como essa formação foi historicamente instituída no País, desde o século XIX.

Embora sua contribuição à reformulação dos cursos de licenciatura tenha se dado em diversos aspectos, tomaremos como foco suas ideias sobre a preparação pedagógica, no que tange à dimensão prática. É assim que se explica, portanto, uma afirmação que ganha destaque no mencionado parecer: "é de se estranhar que até agora, entre as exigências oficiais para a formação do magistério, ainda não figurasse a Prática de Ensino com o merecido relevo". A constatação comprova que, um ano após a aprovação da primeira LDB (Lei 4.024/61), esse componente ainda não integrava de fato e de direito a formação docente, sendo entendido "mais como tema de programa do que como objeto de um mínimo curricular", nas palavras do conselheiro. A preocupação com uma formação que considerasse a

3. Não há como não ver aí uma continuidade com o que repercutira Lourenço Filho, ainda nos anos 1930 e 1940 , a respeito do problema da preparação prática para o magistério, a exemplo do ensaio publicado em 1945, cuja referência completa é encontrada ao final do artigo. 
aprendizagem de métodos e procedimentos de intervenção na realidade escolar é tributária de uma política de formação docente da concepção técnico-científica, que esposava Chagas. Essa preocupação só terá consequência a partir da reforma universitária de 1968, conforme assinala Fávero (1992). Nesse sentido, a Prática de Ensino na formação do professor, sob a forma de estágio curricular, é obra da reforma educacional do regime militar, instalado com o golpe de 1964.

Chagas (1962) pretendia que se reconhecesse a insuficiência da formação docente que não possibilitasse "o necessário realismo àquelas abordagens mais ou menos teóricas da atividade docente". Ora, se a apreciação do conselheiro indicava aspectos novos na abordagem da formação prática do professor, há nela também certo vezo teórico. Só o mundo da escola emprestaria "realismo" à formação docente que se praticava, o que remete à análise de volta à velha dissociação entre teoria e prática. Quando da análise de concepções de formação em confronto naquele momento, Chagas (1962) denominou de conteudística aquela que erigia o "conhecimento [de um campo disciplinar] à categoria de fim em si mesmo", bem como não hesitou em chamar de pedagogismo o enfoque que admitia a formação centrada em aspectos técnico-profissionais. Sua posição apontava para uma solução de equilíbrio entre a temática do ensino e a da formação prática e técnica para realizá-lo. Ao fim e ao cabo, as promessas não se configuraram, uma vez que o anunciado como alternativa aos vieses da formação era também um limite da política educacional do período.

No período pós-64, as reformas educacionais instituem, no bojo da reforma universitária de 1968, a obrigatoriedade da Prática de Ensino, sob o formato de estágio supervisionado ${ }^{4}$, situação formadora em que o "aluno-mestre será assistido por professores especialmente designados para orientá-lo”, conforme o art. 2. ${ }^{\circ}$ da Resolução CFE n. ${ }^{0} 9 / 69$.

Como componente curricular, a Prática de Ensino assume, definitivamente, 0 formato com o qual ficou conhecido: estágio curricular supervisionado, ou seja, espaço pré-profissional em que o estudante tem contato direto com a escola campo de estágio e seu cotidiano. Sob a supervisão de um professor da instituição formadora, o estágio oportuniza a realização de atividades diversas de observação direta da escola, objetivando a compreensão de sua organização e dinâmica. 0 espaço da sala de aula é também privilegiado, nele se desenvolvem atividades que possibilitam o aprendizado de cunho didático, técnico e prático, relativo ao ensino. Enfim, a Prática de Ensino assenta-se, assim, no binômio observação e intervenção. (Freitas, 1996)

Essa medida impacta tanto o campo da formação como da profissionalização

4. As influências do pensamento de Valnir Chagas nas definições legais dessa época são conhecidas.. 
docente, pois passa-se a condicionar a emissão de registro que sanciona a habilitação profissional do professor ao cumprimento da Prática de Ensino da "matéria de habilitação".

Algumas iniciativas de modernização do estágio são experimentadas, sobretudo, a partir dos anos 1970. Atividades de microensino preveem o treinamento de técnicas em que o futuro professor desenvolve habilidades em situação de controle, sob o pressuposto de que a atividade docente precisava ser cientificamente ensinada e aprendida. Esse esforço inovador estava, à época, fortemente lastreado pela corrente pedagógica tecnicista. 0 que dera os primeiros passos nos anos 1940 e 1950 conhecia então um momento de consolidação. Conduzidas por um regime autoritário, as políticas de formação instituem-se como práticas sociais em que os meios de ensino prevalecem sobre as finalidades educacionais, em que a eficácia, a eficiência e a produtividade presidem a gestão dos processos educacionais. Enfim, a formação docente instalava-se, em definitivo, no "reino da competência técnica", balizado pela neutralidade política do conhecimento, da educação e do ensino, com ênfase na dimensão técnica do processo de ensino e aprendizagem.

No final da década de 1970, essa visão de estágio, de resto, vai de par com a de formação de professores e começa a sofrer questionamentos de pesquisadores em educação, de formadores de educadores e dos movimentos de professores em defesa da democratização da escola e de uma prática educativa transformadora. São expressivas da agenda política desse momento as recomendações do I Encontro Nacional da Comissão Nacional de Reformulação dos Cursos de Formação do Educador (CONACFE), promovido pela Secretaria de Ensino Superior (SESu/MEC), em Belo Horizonte. (Freitas, 1996, p. 22)

Ao longo dos anos 1980, críticas incidem sobre diferentes dimensões da formação docente. Instituições como a Fundação Carlos Chagas, a Associação Nacional de Educação (ANDE) e os cursos de pós-graduação em educação passam a divulgar resultados de investigações que problematizam o fracasso da escola em relação com os modelos de formação de professor, constituindo análises de cunho sociológico, baseadas principalmente em várias correntes das teorias críticas. A formação do professor deixa de ser analisada por aspectos puramente técnicos e legais, em função de abordagens de caráter tecnicista ou jurídico, para ser entendida no contexto sócio-histórico em que ela se insere. Pensada, portanto, com a finalidade de, de um lado, apreender os determinantes sociais da formação e, por outro, repensar a função da escola e a formação de cidadãos críticos. (Silva et al., 1991)

No âmbito pedagógico, as críticas destacam o caráter excessivamente teórico, bem como o distanciamento entre a teoria e a prática pedagógica na educação básica. As análises apontam ainda para as dificuldades da Prática de Ensino: 
escolas desinteressadas em receber estagiários; dificuldade no relacionamento entre professor regente da escola e estagiário; observação do campo distanciada dos objetivos institucionais; transformação do estágio em um conjunto de atividades formais e burocráticas; ausência de um plano integrado entre instituição formadora e escola; precariedade no acompanhamento do estágio; estágio entendido como atividade terminal da formação e como "polo prático".

0 período em tela demonstra avanços nas análises, que vão ganhando corpo e densidade. Um amplo movimento de educadores e pesquisadores em educação pugna pela reformulação dos cursos de licenciatura, com base no princípio da "docência como a base da identidade profissional dos profissionais da educação". (Silva, 2003, p. 68 - 79)

Os diversos problemas apontados receberão, porém, um tratamento pontual de algumas instituições de ensino superior e de alguns cursos. Será necessário aguardar as reformas educacionais dos anos 1990 para que elas ganhem foros de política educacional de formação de professores.

\section{Formação de professores no contexto das reformas educacionais dos anos 1990}

As reformas educacionais são obra da vaga neoliberal que varre as políticas de estado em diversos países, e o Brasil não fica isento. São elas responsáveis pela redefinição da concepção e da política de formação de professores. Julgamos importante assinalar que as mudanças que se operam no plano da formação se fazem de par com a delimitação no nível da lei maior da educação (Lei 9.394/96). A LDB introduz alterações quanto aos espaços institucionais, princípios e formatos da formação docente. Para isso, institui os institutos superiores de educação (ISE) para abrigar a formação de professores da educação infantil ao ensino médio e o curso normal superior como alternativa ao curso de pedagogia quanto à formação de professores. Sinalizaria, assim, para uma política educacional tendente a efetuar um nivelamento por baixo, uma vez que os ISE surgem como "instituições de nível superior de segunda categoria, provendo uma formação mais aligeirada, mais barata, por meio de cursos de curta duração". (Saviani, 2009, p.148)

No âmbito das mudanças, destacam-se as definições quanto às incumbências do professor (art. 13 da LDB), com impacto no plano da formação. A LDB traça um perfil profissional do professor, independentemente de a docência se realizar de forma multidisciplinar ou especializada, por área de conhecimento ou disciplina, para crianças, jovens ou adultos, sem se referir, portanto, ao exercício da atividade docente em um nível, etapa ou modalidade de ensino específico. 
Dentre os princípios que norteiam a política de formação de professor destacase a ideia de que a formação docente é um processo autônomo, com identidade própria, desvinculado, portanto, da formação do bacharel, mas sem perder de vista a necessária articulação com institutos, departamentos e cursos de áreas específicas, bem como com as escolas do sistema de educação básica. A essa ideia se associa outra, segundo a qual a formação docente propiciaria ao estudante o domínio de diversos saberes e valorizaria as experiências e os saberes experienciais.

A primeira proposição serviria para a superação da situação de subsunção dos cursos de licenciatura aos de bacharelado. Trata-se, pois, de ruptura para com as políticas de formação docente praticadas desde meados dos anos 1930. Os críticos dessa formulação a atacam injustamente, não reconhecendo a prudência de que ela se reveste, pois se trata de assumir a autonomia da formação do licenciado em relação à do bacharel como pressuposto curricular, porém sem perder de vista a necessária articulação entre os saberes pedagógicos e os saberes das áreas disciplinares de referência.

Por outro lado, a segunda proposição reconhece a docência como uma atividade complexa, cujos elementos constituintes, de natureza epistêmica, são diversos e complementares. A diversidade de saberes constitui pressuposto, na medida em que supõe a necessidade de o professor em formação buscar apropriar-se não somente de saberes disciplinares, como entendiam as práticas tradicionais, mas de um conjunto de saberes plurais, de natureza profissional, curricular, cultural e outros. Dentre esses, destacam-se os saberes experienciais. Originários da prática cotidiana dos professores e do confronto com as condições da profissão, são desenvolvidos no exercício das funções e da prática profissional, incorporando-se à experiência individual e coletiva (Tardif, 2002). Nessa perspectiva, considerando que "todo saber implica um processo de aprendizagem e de formação", diz Tardif (2002, p. 35), produzir situações de docência a serem observadas e refletir sobre a experiência docente, planejar e realizar intervenções sobre o ensino, com o uso dos diversos saberes, é papel do estágio. Isso implica, no plano curricular, considerar - necessário equilíbrio entre saberes disciplinares e saberes profissionais (pedagógicos, educacionais, culturais etc.) na composição da matriz do curso da formação docente.

\section{A Prática de ensino na atual LDB}

Em seu artigo 65, a LDB determina que a formação docente incluirá prática de ensino de, no mínimo, trezentas horas. 0 aumento de carga horária 
pode ser considerado, a princípio, um avanço na medida em que aumenta a permanência do licenciando em campo de estágio para quase o dobro do tempo anteriormente previsto. Bem mais que um acréscimo quantitativo de horas, o dispositivo, ao ampliar as exigências, demanda precisões relativas aos conteúdos das atividades do estágio.

No ano que se seguiu à edição da LDB, o Conselho Nacional de Educação (CNE) estabelece, mediante o Parecer n. ${ }^{\circ} 744$ (Brasil, 1997), orientações para cumprimento da Prática de Ensino, fixando o entendimento de que "a prática de ensino deverá constituir o elemento articulador entre formação teórica e prática pedagógica com vistas à reorganização do exercício docente em curso." As atividades de estágio dizem respeito às práticas profissionais atinentes ao professor da educação básica, envolvendo, além da observação e regência de classe, ações relativas ao planejamento, à análise e à avaliação do processo pedagógico, bem como às diversas dimensões da dinâmica escolar: gestão, interação de professores, relacionamento escola e comunidade e relações com a família dos alunos.

0 mesmo parecer fixa ainda a obrigatoriedade de supervisão, a cargo da instituição formadora, atividade que não deve ultrapassar vinte e cinco por cento do total do tempo previsto para a prática de ensino.

Documento de grande importância, as Diretrizes Curriculares Nacionais para a Formação de Professores - DCNFP (Resoluções CNE/CP n. ${ }^{\circ}$ s 01 e 02/2002) têm por finalidade, como o nome indica, fixar macrodiretrizes que passam a orientar, em nível nacional, a organização de todo e qualquer curso de formação de professor, aí incluídos a prática e o estágio. Para superar o modelo tradicional de formação docente, as DCNFP assimilam os conteúdos dos debates social e acadêmico e identificam as questões a serem enfrentadas.

Denunciam a fragilidade do projeto pedagógico por este desconsiderar 0 necessário equilíbrio entre saberes disciplinares e saberes pedagógicos na composição da matriz curricular da formação docente, bem como por minimizar o tratamento de questões da ordem do ensinar e do aprender e as especificidades de diferentes níveis e modalidades da educação básica. Ao catapultar o ensino e a aprendizagem ao centro da formação, terminam por provocar a invisibilidade de questões atinentes ao contexto sócio, político e cultural, bem como o debate filosófico sobre as finalidades educacionais e sua historicidade. Empobreceria, assim, o debate em matéria de política educacional e sua função social como política pública.

No que concerne à dinâmica curricular, as DCNFP denunciam ainda o divórcio entre conhecimentos teóricos e prática, bem como uma concepção restrita de prática. Por isso, na organização da matriz curricular do curso 
de licenciatura, propõem um eixo que articule teoria e prática, instituindo a "prática como componente curricular", perpassando a matriz. (Brasil, 2001, p. 39)

Outra inovação curricular introduzida diz respeito ao estágio obrigatório, a ser vivenciado ao longo do curso, com início na segunda metade, com a finalidade de romper com seu caráter terminal e de permitir a aproximação com as diferentes dimensões da prática profissional. Assim, como o "exercício de qualquer profissão é prático, na medida em que se trata de 'fazer algo' ou “ação'”, diria Pimenta (2001, p. 28), e considerando que,

como não é possível que o curso assuma o lugar da prática profissional (que o aluno exercerá quando for possível), o seu alcance será tão somente possibilitar uma noção de prática, tomando-a como preocupação sistemática no currículo do curso. (Pimenta, 2001, p. 28)

$\mathrm{Na}$ verdade, as diretrizes não tiveram o condão de alterar o dilema que assoma a formação docente desde que ela se instituiu no Brasil, dilema, segundo Saviani (2009, p. 151), cuja raiz está na "dissociação entre os dois aspectos indissociáveis da função docente: a forma e o conteúdo". 0 quadro tende a agravar-se quando se considera o peso relativo que a cultura disciplinar assume nas universidades e o papel que essas instituições assumem para o conjunto da educação superior e básica. Nesse sentido, passada mais de uma década de sua edição, permaneceria inalterado o quadro segundo o qual as unidades acadêmicas universitárias responsáveis pelos conteúdos pedagógicos (centro/faculdades de educação) tenderiam a seguir reunindo "os especialistas das formas abstraídas dos conteúdos, enquanto os institutos e faculdades correspondentes às disciplinas que compõem os currículos escolares reúnem os especialistas nos conteúdos abstraídos das formas que os veiculam". (Saviani, 2009, p. 151)

Por tal razão, confrontados com a ideia de estágio curricular supervisionado como aproximação entre a universidade pública e a escola de educação básica, porque pautada em um projeto integrado e integrador de formação, que busca torná-lo um processo de investigação, explicação, interpretação e intervenção da/na realidade (da escola, da sala de aula, seus sujeitos e relações), no qual a integração entre teoria e prática seja um elemento estruturador, buscamos, num segundo momento do texto, analisar uma proposição de estágio em uma universidade pública federal, situada no Nordeste. 


\section{Estágio curricular como eixo estruturador da formação de professores: uma proposta em diálogo com o debate}

Na tentativa de responder aos desafios de promover uma formação de professores fundada em bases sólidas, na unidade teoria e prática, numa abordagem de totalidade e como investigaçã $0^{5}$, fundamentos que compõem as DCNFP da formação de professor para o magistério na educação básica, instituições como a Universidade Federal de Pernambuco (UFPE), seguida de outras IES sintonizadas com os mesmos princípios, têm buscado tomar o Estágio Supervisionado como um componente curricular capaz de promover aproximações e vivências de prática investigativa sobre a escola, a docência e o ensino, tomados como objeto de conhecimento e de formação profissional. Superam assim, os modelos que, predominantemente, caracterizavam-se como pratica de final de curso.

0 estágio curricular como eixo estruturador da formação docente passa a ser entendido como um componente curricular e uma prática formadora que perpassa o processo formativo, estendendo-se ao longo do curso de formação profissional, em que se efetiva uma relação entre o espaço de formação inicial e o espaço do trabalho profissional, sob a responsabilidade de uma equipe de professores. Assim sendo, é entendido como uma prática formadora processual, coletiva e interdisciplinar que se apoia em princípios, organização, conteúdos e abordagens diferentes daqueles que vêm orientando-o, predominantemente, nos cursos de formação de professores.

A proposta em análise ${ }^{6}$ caracteriza o estágio curricular como um trabalho coletivo e interdisciplinar, assumido tanto por professores de disciplinas de conteúdo pedagógico que trata o fenômeno educativo e o ensino, nas suas diferentes dimensões, como por professores de conteúdos curriculares específicos do curso de formação profissional. Portanto, os conteúdos da formação profissional são também conteúdos do estágio quando tomados como ferramentas teóricas e metodológicas que norteiam o olhar, a análise e a intervenção pedagógica na escola.

5. A proposta inspira-se em princípios formulados pela ANFOPE. Ver, entre outros, Pimenta, 2001; Pimenta e Lima, 2005/2006.

6. Trata-se da proposta de estágio supervisionado, discutida no Centro de Educação da UFPE, desde 1997, no Colegiado de Pedagogia, em sessões de Pedagogia em Movimento, eventos acadêmicos, que serviu de referência para a reformulação do componente em outras IES. Ver Almeida (2008). 


\section{0 estágio como componente curricular estruturador da formação docente}

Vislumbrada a possibilidade de se articularem saberes e prática, o estágio assume, como dito antes, novas perspectivas com o aprofundamento dos estudos no campo do currículo, da didática, da profissionalização e dos saberes docentes. Os princípios, a estrutura e a dinâmica que caracterizam esse componente curricular atribuem-lhe um caráter fundante da formação profissional docente, por apontar, principalmente, possibilidades de aproximação sucessiva entre instituição formadora e instituição do exercício da profissão, os saberes da formação e os problemas profissionais gerados e explicitados nos espaços de formação e de exercício da profissão, bem como de trocas a serem efetivadas entre docentes experientes, iniciantes e formadores. Considerando tais questões, procederemos, primeiramente, à análise dos princípios nos quais se baseia o estágio, seguida de discussão sobre sua dinâmica e estrutura.

\section{Princípios do estágio supervisionado numa perspectiva de trabalho coletivo, interdisciplinar e investigativo}

Os princípios que norteiam o estágio supervisionado nessa Proposta são: (1) a centralidade na formação profissional e na formação profissional docente situa o componente curricular com a função de introduzir o professor/a em formação na temática educação e trabalho como campo profissional, categoria teórica e exercício de uma profissão; (2) a aproximação entre os espaços de formação e de exercício profissional tem como referência teórica os saberes profissionais tanto numa perspectiva de análise institucional e das práticas pedagógicas como pelo uso desses conteúdos na formação inicial e continuada dos professores; (3) o estágio como processo de investigação pedagógica procura afirmar a indissociabilidade entre o ensino e a pesquisa, fomentando uma formação profissional pautada nos processos de construção do conhecimento, por meio da apropriação dos problemas da profissão.

Esses princípios estão traduzidos na organização da proposta, nos conteúdos selecionados como temáticas essenciais à formação profissional e nos processos metodológicos definidos.

No que se refere à organização, opta-se pelo formato de ciclos como unidades de conteúdos e práticas que, mediante uma abordagem didática, usa os saberes profissionais disponíveis no espaço de formação profissional para compreender, explicar e atuar no espaço de exercício pré-profissional. 0 formato escolhido 
propicia, também, a sequência, a continuidade, a ampliação e o aprofundamento dos saberes profissionais que vão sendo adquiridos e, ainda, procura transformar os saberes da experiência produzidos no cotidiano da prática escolar em saberes da formação, a serem tratados na instituição formadora. Portanto, os ciclos têm a função de articular os conhecimentos gerados nas diversas práticas construídas e em construção nos espaços de formação profissional e de exercício da profissão, por meio de uma diversidade de situações de ensino e de aprendizagens.

A proposta foi formulada em quatro ciclos com objetivos, conteúdos temáticos e procedimentos que, de um lado, permitem uma visão de conjunto da instituição escola como espaço de observação, formação profissional e intervenção pedagógica; e, de outro, podem promover a aproximação com campos do conhecimento e, consequentemente, com profissionais de diversos cursos de formação de professores, as licenciaturas.

\section{Estrutura e Dinâmica dos Ciclos da Prática de Ensino}

Os ciclos do estágio curricular e a abordagem didática têm a função de articular, por meio de eixos temáticos, os saberes disciplinares da formação profissional e os saberes da experiência produzidos tanto no processo de formação profissional quanto no exercício da profissão. Adotará para tanto procedimentos básicos como a observação, os registros e os seminários temáticos, além de procedimentos específicos que caracterizarão cada ciclo e responderão pelos seus objetivos.

\section{1. ${ }^{\circ}$ Ciclo: 0 olhar para o espaço de aprendizagem e de inserção profissional - a escola}

Esse ciclo inicia a Prática de Ensino, no quarto período, e tem a finalidade de contribuir para que o professor em formação conheça a escola como instituição em sua globalidade a partir de quatro temáticas: (1) a organização escolar, estudo das instituições escolares, da escola e dos seus profissionais, das relações sociais na escola e da gestão escolar; (2) as condições de exercício do trabalho educativo, compreendidas pela análise das condições materiais, situação dos profissionais da educação e da formação profissional - inicial e continuada; (3) a produtividade escolar abordada a partir do conhecimento dos índices dos resultados escolares, tomando como referência as bases e os processos de construção do fracasso e sucesso escolar; (4) a história da instituição escolar e a sua função social por um processo de análise dos discursos oficiais e pedagógicos e os resultados escolares. 
Em resumo, esses temas e seus desdobramentos têm a função de oferecer uma base de conhecimentos sobre a instituição escolar como organização, funcionamento e resposta social, de modo que o professor em formação vá construindo uma visão de totalidade da escola, identificando os problemas profissionais, escolares e de ensino por meio do contato direto com a realidade concreta e a base teórica disponível e atual.

A base teórica explicativa e argumentativa que subsidia esse ciclo está representada por conteúdos relativos à sociedade, à educação, à escola e à profissão como categorias teóricas, como política educacional e como prática pedagógica, abordados por meio dos componentes curriculares: Fundamentos Sócio-histórico-filosóficos da Educação; Tópicos de Política Educacional e Legislação Escolar; Fundamentos Socioantropológicos da Educação Brasileira; Educação e Trabalho.

Nesse ciclo, a observação dirigida e os seminários temáticos constituem-se em situações básicas de aprendizagens, sob a responsabilidade do professor de Prática de Ensino e a coordenação de professores responsáveis por componentes curriculares/disciplinas de conteúdo pedagógico.

\section{Ciclo: o olhar para as diferentes relações no interior da sala de aula e os saberes e competências necessários ao exercício profissional - a sala de aula}

Apoiado no ciclo anterior, este busca conhecer as relações no interior da sala de aula voltando as preocupações para os rituais e os processos interativos do ambiente da aula. Duas temáticas foram destacadas como essenciais: (1) a relação entre os atores pedagógicos, efetivada pela observação dos processos interativos entre professor - estudante, professor - professor, estudante - estudante, grupo - outros profissionais da educação, professor - família do estudante; e (2) a organização e o modo de funcionamento da sala de aula analisada do ponto de vista espacial - como organização e movimento - e do ponto de vista didático-pedagógico. As situações básicas de ensino, de aprendizagem e de avaliação também são tomadas como objetivos de avaliação.

Nesse ciclo, são indispensáveis para compreender o movimento da sala de aula os conteúdos relativos ao pensamento pedagógico, as abordagens e os processos didáticos utilizando-se os componentes curriculares: Fundamentos Psicológicos da Educação; Bases teóricas e metodológicas para a investigação; Organização-direçãoavaliação da educação. A observação dirigida e os seminários temáticos continuam como situações básicas de aprendizagens e estarão sob a responsabilidade do professor de Prática de Ensino e sob a coordenação de professores/as responsáveis por componentes curriculares/disciplinas de conteúdo pedagógico. 


\section{$3^{\circ}$ Ciclo: intervenção didático-pedagógica de conhecimento específico em sala de aula - prática de ensino stricto sensu}

Nesse momento da Prática de Ensino, o ciclo tem a finalidade de preparar as situações de intervenção pedagógica e de vivenciá-las em sala de aula e na escola. Espera-se que as informações sobre a cultura escolar e sobre a ecologia da sala de aula, objetos dos ciclos anteriores, constituam o repertório de saberes do professor em formação, contribuindo para as atividades de direção da sala de aula. Em outros termos, espera-se que a vivência dos dois primeiros ciclos, realizada mediante estudo, observação e socialização, tenha oportunizado uma análise sobre a organização e o funcionamento da escola e da sala de aula, permitindo um trabalho de elaboração e de vivência pedagógica. Como procedimentos utilizar-se-ão as competências básicas de organização do espaço e dos materiais didáticos; de direção de aula, de estudos e de reuniões; e de avaliação do ensino e da aprendizagem.

Em síntese, a temática (1) organização consiste em duas fases de trabalho de natureza diferenciada, mas complementares: uma referente à preparação da intervenção pedagógica que se realiza a partir e como análise do grupo sala de aula, da proposta curricular, dos programas e dos planos; e a outra, alicerçada nesta, se faz como elaboração do projeto didático, de situações de ensino e de avaliação e seleção/preparação de material didático. (2) A direção refere-se à vivência da docência em situação de aula em diferentes formatos: em situação coletiva, em situação de grupo, como atendimento individual e também como atividade de campo. Além da docência em sala de aula, o exercício pré-profissional concebe a direção de estudos, de reuniões e de situações avaliativas como aprendizagens da docência que nascem e retornam como demandas da sala de aula. E, por fim, a (3) avaliação ocupa-se do ensino e da aprendizagem como vivência e análise dos resultados individuais e coletivos em sala de aula e como prática coletiva no conselho de classe.

\section{$4^{\circ}$ Ciclo: Realização de estudo monográfico sobre a escola, a sala de aula e ou o ensino}

Esse ciclo é o momento síntese da Prática de Ensino, materializado como trabalho de final de curso. Tem uma função sistematizadora dos conteúdos da formação e da análise do campo de atuação profissional. Assim, a pesquisa pode ser desenvolvida nos diferentes campos do saber escolar e sobre os diferentes objetos de ensino e modalidades. Caracteriza-se como um ciclo de orientação e produção do conhecimento científico, sob a responsabilidade do professor de Prática de Ensino e dos professores de conteúdos curriculares específicos do curso objeto da formação docente, apresentado 
por meio de uma monografia como resultado da formação de professor. A orientação estará sob a responsabilidade de um dos professores de conteúdos curriculares específicos ou de conteúdos pedagógicos ou ainda sob a responsabilidade de ambos, de acordo com a natureza do curso e do objeto escolhido. Nesse momento da formação, não há obrigatoriedade de trabalho na instituição escolar, o tempo é reservado para a sistematização e, quando necessário, para completar, esclarecer ou aprofundar informações.

Em outros termos, os critérios de sequência, continuidade, ampliação e aprofundamento dos conceitos, competências e vivências na proposta são representados pela exigência de um trabalho de final de curso a ser apresentado no estágio.

\section{Vivência e desafios da proposta: à guisa de considerações finais}

A Prática de Ensino em forma de estágio supervisionado, assim concebida e vivenciada na UFPE, indicou aproximações que ampliam e reforçam resultados de pesquisas desenvolvidas por Rocha (2008) e Lemos (2006), os quais mostram a importância da intervenção e investigação na escola básica desde os primeiros períodos do curso. Resulta da relação interinstitucional - espaço de formação e espaço do exercício da profissão - a familiarização com as questões concretas da organização da escola e das relações na comunidade escolar, a construção de saberes oriundos da dinâmica da sala de aula, somando-se o exercício investigativo, instrumentalizado pela observação efetiva e reflexiva, no trato às questões e temáticas do cotidiano.

A concepção e a vivência com este componente curricular fazem emergir, também, algumas implicações de ordem prática que merecem medidas de ordem administrativa, pedagógica e metodológica. Entre elas encontram-se: (1) a exigência de reorganização da estrutura curricular do(s) curso(s) de modo que sejam aproximados os componentes curriculares e o "olhar" para a instituição escolar, fundamentando a observação, a discussão e a análise a partir do corpo teórico do curso de formação de professores ${ }^{7}$ (2) a necessidade de formação de grupos de trabalho ou equipes de professores, por campo do conhecimento ou área de ensino, responsáveis por cada ciclo da Prática de Ensino em suas fases de planejamento, efetivação e avaliação num exercício interdepartamental e multidimensional, evidenciando-se assim as contribuições do saber pedagógico e dos saberes curriculares dos campos específicos da formação profissional para o ensino; (3) o trato da Prática de Ensino, como componente curricular na organização curricular, como tempo de formação,

7. No caso da UFPE - Centro de Educação, o processo de discussão no colegiado do curso de pedagogia apontou dois aspectos a serem considerados na implementação do $1^{\circ}$ Ciclo da Prática de Ensino: que a disciplina Educação e Trabalho, ofertada como disciplina optativa em umas das habilitações no $8^{\circ}$ período do curso, deveria tornarse obrigatória para subsidiar as discussões e responder teoricamente às questões relativas aos profissionais da educação e àquelas referentes à profissão e ao trabalho docente, devendo, portanto, ser oferecida no $4 .^{\circ}$ período. 
com visibilidade na organização da carga horária e dos horários dos cursos e das instituições, evitando atitudes espontaneístas e a secundarização desse conteúdo formador e de intervenção pedagógica.

Os estudos desenvolvidos nos últimos anos que analisam os olhares para a proposta e a sua vivência têm revelado o seu caráter inovador e dinâmico (Lemos, 2006; Rocha, 2008; Melo, 2014). A perspectiva processual, transversalizando o processo formativo, coloca o professor em formação em contato direto com a realidade socioeducacional e escolar. Sua inscrição como prática pedagógica mediadora, no seio da formação profissional, levou à sua antecipação no processo formativo, passando a oferta a ocorrer, quase sempre, a partir do início do curso e não na metade do tempo de integralização, como inicialmente vivenciado.

Os processos de aproximação das instituições formadoras e das instituições do exercício profissional, assim como dos saberes da formação e os saberes profissionais também constituem traços inovadores da proposta, embora pouco ainda se tenha avançado na instituição formadora para a recepção dos saberes produzidos no espaço profissional como saberes para a formação. Neste caso, a socialização dos trabalhos de final de curso, que resultam de investigação pedagógica e educacional, pouco tem servido como conteúdo nos processos formativos, ganhando mais ênfase como exercício de desenvolvimento de pesquisa na formação inicial.

Assim, o seminário temático, mecanismo pedagógico que constitui o desenho da proposta como estratégia mediadora, ainda precisa avançar como resposta epistêmica e metodológica. Na proposta, ele carrega a possibilidade de articulação das áreas do conhecimento, dos saberes da formação e do exercício da profissão; socialização de experiências escolares e práticas sociais de ensino, de gestão profissional e ainda como ampliação dos olhares para a problemática socioeducativa. Entretanto, tem se configurado mais como uma disciplina do que como uma estratégia pedagógica na configuração do estágio curricular supervisionado, sob a forma de prática de ensino.

0 estágio apresentado como eixo estruturador da formação de professores apresenta-se, assim, como esforço coletivo para que se construa uma formação sólida de professores, por meio do exercício da pesquisa, no chão da escola. Entretanto, continua a desafiar formadores e pesquisadores a encontrarem estratégias político-pedagógicas para responder às questões postas continuamente e a cada reforma curricular, para que possa consolidar o trabalho coletivo, a relação interinstitucional e a articulação entre os saberes da formação profissional e do exercício da profissão. 


\section{Referências}

ALMEIDA, Lucinalva Andrade Ataíde de. Políticas curriculares para a formação de professores e processos de reformulação curricular nas instituições de ensino superior. 2008. 157f. Tese (Doutorado em Educação) - Universidade Federal de Pernambuco, Recife, 2008.

ANFOPE. Associação Nacional pela Formação dos Profissionais da Educação, Documento Final, IX Encontro, Campinas, 1998.

ARAÚJO, Marta Maria de. Plasticidade do Plano de Reconstrução Nacional de Anísio Teixeira. Educativa, Goiânia, v. 10, n. 1, pp. 9-27, jan./jun. 2007.

BATISTA NETO, José. Formação de professor, profissionalização e cultura docente: concepções alternativas ao professor profissional. In: MERCADO, Luis Paulo Leopoldo; CAVALCANTE, Maria Auxiliadora da Silva. Formação do pesquisador em educação: profissionalização docente, políticas públicas, trabalho e pesquisa. Maceió: EDUFAL, 2007.

BATISTA NETO, José; SANTIAGO, Eliete. Formação de professores e prática pedagógica. Recife: Editora Massangana, 2006.

BRASIL. CNE/CES. Parecer no 744, de 03 de dezembro de 1997. Orientações para cumprimento do artigo 65 da Lei 9.394/96 - Prática de Ensino. Relatora: Silke Weber. Disponível em: <www.portal.mec.gov.br>. Acesso em: 04 mar. 2014.

BRASIL. CNE/CP. Parecer no 21, de 6 de agosto de 2001. Institui duração e carga horária dos cursos de Formação de Professores da Educação Básica, em nível superior, curso de licenciatura, de graduação plena. Disponível em: <www.portal.mec.gov.br >. Acesso em: 04 mar. 2014.

BRASIL. CNE/CP. Parecer no 9, de 8 de maio de 2001. Institui Diretrizes Curriculares Nacionais para a Formação de Professores da Educação Básica, em nível superior, curso de licenciatura, de graduação plena. Diário Oficial [da] República Federativa do Brasil, Brasília, DF, 18 de janeiro de 2002. Seção 1, p. 31.

BRASIL. CNE/CP. Resolução no 1, de 18 de fevereiro de 2002. Institui Diretrizes Curriculares Nacionais para a Formação de Professores da Educação Básica, em nível superior, curso de licenciatura, de graduação plena. Brasília, DF. Disponível em: <www. portal.mec.gov.br>. Acesso em: 04 mar. 2014.

BRASIL. CNE/CP. Resolução no 2, de 19 de fevereiro de 2002. Institui duração e carga horária dos cursos de licenciatura, de graduação plena, de formação de professores da Educação Básica em nível superior. Brasília, DF. Disponível em: <www.portal.mec.gov.br>. Acesso em: 04 mar. 2014.

BRASIL. Congresso Nacional. Lei n. 4.024, de 20 de dezembro de 1961. Fixa as diretrizes e bases da educação nacional. Documenta, Brasília, n.1, 1962.

BRASIL. Conselho Federal de Educação. Parecer n 292, de 14 de novembro de 1962. Trata da parte pedagógica dos currículos mínimos relativos aos cursos de licenciatura. Relator: Valnir Chagas. Documenta, Brasília, n. 10, pp. 95-100, 1962. 
BRASIL. Decreto-lei no 8.530, de 2 de Janeiro de 1946. EMENTA: Lei Orgânica do Ensino Normal. Diário Oficial da União. Poder Executivo, Rio de Janeiro, DF - Seção 1, p.116. BRASIL. Lei no 9394/96, de 20 de dezembro de 1996. Estabelece as diretrizes e bases da educação nacional. Diário Oficial [da] República Federativa do Brasil, Poder Executivo, Brasília, DF, 23 de dezembro de 1996.

CANDAU, Vera Maria. Revitalização do Curso Normal. IV Conferência Brasileira de Educação (CBE), 4, 1986, Goiânia, Anais..., Goiânia, CBE, 1986, 1, pp. 502-508.

CANDAU, Vera Maria; LELIS, Isabel. A relação teoria-prática na formação do educador. Tecnologia Educacional, Associação Brasileira de Tecnologia Educacional, Rio de Janeiro, n. 5, pp. 12-18, nov.-dez. 1983.

FÁVERO, Maria de Lourdes. Universidade e estágio curricular: subsídios para discussão. In: ALVES, Nilda (Org.). Formação de professores: pensar e fazer. São Paulo: Cortez, 1992. pp. 53-71.

FAZENDA, Ivani Catarina Arantes. O papel do estágio nos cursos de formação de professores. In: PICONEZ, Stela Bertholo (Coord.). A prática de ensino e o estágio supervisionado. Campinas, SP: Papirus, 1994. pp. 53-62.

FREITAS, Helena Costa Lopes de. O trabalho como princípio articulador na prática de ensino e nos estágios. Campinas, SP: Papirus, 1996.

LEMOS, Ana Raquel Pereira. A prática de ensino sob forma de pesquisa e prática pedagógica no curso de pedagogia. 2006. Trabalho de Conclusão Curso (Pedagogia), Universidade Federal de Pernambuco, Recife, 2006.

LOURENÇO FILHO, Manoel Bergström. Prática de ensino. In: LOURENÇO FILHO, Ruy (Org.). A formação de professores: da Escola Normal à Escola de Educação. Brasília: Instituto Nacional de Estudos e Pesquisas Educacionais, 2001, pp.51-60.

MELLOWKI, M hammed; GAUTHIER, Clermont. O professor e seu mandato de mediador, herdeiro, intérprete e crítico. Educação e Sociedade, Campinas, v. 25, no 87, pp. 537571, maio/ago. 2004.

MELO, Maria Julia Carvalho de. Os sentidos sobre estágio supervisionado e as contribuições para a prática docente do professor com experiência. 2014. 189p. Dissertação (Mestrado em Educação) - Universidade Federal de Pernambuco, Recife, 2014.

PICONEZ, Stela Bertholo. A prática de ensino e o estágio supervisionado: a aproximação da realidade escolar e a prática da reflexão. In: estágio supervisionado. Campinas, SP: Papirus, 1994. pp. 15-38.

PIMENTA, Selma Garrido. O estágio na formação de professor: unidade teoria e prática? 4. ed. São Paulo: Cortez, 2001.

PIMENTA, Selma Garrido; LIMA, Maria Socorro Lucena. Estágio e docência: diferentes concepções. Revista Poíesis, vol. 3, números 3 e 4, pp.5-24, 2005/2006.

ROCHA, Áurea Maria Costa. A formação de professores e a construção dos saberes da docência no curso de Pedagogia da UFPE. 2008. 166p. Dissertação (Mestrado em Educação) - Universidade Federal de Pernambuco, Recife, 2008.

SAVIANI, Dermeval. A nova lei de educação: LDB: trajetórias, limites e perspectivas. 9. 
ed. Campinas, SP: Autores Associados, 2004.

Formação de professores: aspectos históricos e teóricos do problema no contexto brasileiro.Revista Brasileira de Educação, v. 14, no 40. jan./abr. 2009, pp. 143155.

SILVA, Rose Neubauer et al. Formação de professores no Brasil: um estudo analítico e bibliográfico. São Paulo: Fundação Carlos Chagas, REDUC, 1991.

SILVA, Carmem Silvia Bissolli da. Curso de Pedagogia no Brasil: história e identidade. Campinas: Autores Associados, 2003.

TARDIF, Maurice. Saberes docentes e formação profissional. Petrópolis, RJ: Vozes, 2002. VEIGA, Ilma Passos d'Alencastro et al. Docência: uma construção ético-profissional. Campinas, SP: Papirus, 2005.

ZEICHNER, Kenneth M. A formação reflexiva de professores: idéias e práticas. Lisboa: Educa e autor, 1993.

Recebido em julho de 2014 Aprovado em dezembro de 2014

José Batista Neto é doutor em Ciências de Educação pela Université Paris V (René Descartes) e professor associado do Departamento de Métodos e Técnicas de Ensino da Universidade Federal de Pernambuco (UFPE). E-mail: josebnđuol.com.br

Eliete Santiago é doutora em Ciências da Educação pela Université de Paris V (René Descartes) e professora titular do Departamento de Administração Escolar e Planejamento Educacional da UFPE. E-mail: mesantiagoduol.com.br 